\title{
CHLAMYDIA TRACHOMATIS INFECTION IN INFERTILE AND PREGNANT WOMEN IN SOUTHERN BRAZIL
}

\author{
Deborah Beltrami Gomez¹, Ivan Sereno Montenegro', \\ Guilherme Rezende Baade ${ }^{2}$, Paula Barros Terraciano', \\ Raquel de Almeida Schneider ${ }^{3}$, Débora Helena Zanini Gotardi ${ }^{3}$, \\ Victória Furquim dos Santos Cardoso ${ }^{3}$, Eduardo Pandolfi Passos ${ }^{1}$
}

Clin Biomed Res. 2016;36(3):117-123

1 Graduate Program in Health Sciences: Gynecology and Obstetrics, Universidade Federal do Rio Grande do Sul (UFRGS) Porto Alegre, RS, Brazil.

2 School of Medicine, Universidade Federal do Rio Grande do Sul (UFRGS). Porto Alegre, RS, Brazil.

3 Undergraduate Research Program: Laboratory of Embryology and Cellular Differentiation, Hospital de Clínicas de Porto Alegre (HCPA). Porto Alegre, RS, Brazil.

Corresponding author: Deborah Beltrami Gomez deborahbeltrami@hotmail.com Universidade Federal do Rio Grande do Sul (UFRGS)

Rua Ramiro Barcelos, 2350, Sala 1126, Bairro Santa Cecília. 90035-903, Porto Alegre, RS, Brazil.
Conclusion: There is a high prevalence of CT IgG antibody in Brazilian pregnant and infertile women, but we found a low prevalence of positive PCR in the urine samples. CT antibodies were associated with sexual behavior and smoking.

Keywords: Chlamydia trachomatis; Chlamydia infections; prevalence; nucleic acid amplification techniques; infertility; female; fluorescent antibody technique. 
Chlamydia trachomatis (CT) is the most prevalent sexually transmitted bacterial infection ${ }^{1}$. According to the World Health Organization (WHO), 131 million people were infected worldwide in $2012^{2}$. It affects mainly young, sexually active women ${ }^{3}$. Most infections with CT are asymptomatic ${ }^{4}$. In women, untreated infection may lead to pelvic inflammatory disease (PID) with the risk of serious reproductive complications, such as chronic pelvic pain, tubal factor infertility (TFI), and ectopic pregnancy ${ }^{5}$. Studies suggest that chlamydial infection in pregnant women can enhance the risk of preterm labor, low birth weight, and perinatal death ${ }^{6}$. Additionally, CT vertical transmission usually causes neonatal inclusion conjunctivitis and/or pneumonia ${ }^{7}$.

Among various methods available for $\mathrm{CT}$ infection diagnosis, nucleic acid amplification tests (NAATs) are preferable due to their high sensibility and specificity and because they can be performed using non-invasive samples, such as urine and vaginal swabs $^{8}$. Chlamydia immunoglobulin (Ig) $\mathrm{G}$ antibodies persist for years even after antibiotic treatment and are used as markers of a past infiltrating CT infection ${ }^{9}$.

In Brazil, since routine screening is not recommended by the public health system, there are few data on CT infection. The purpose of this study was to estimate the prevalence of $\mathrm{CT}$ infection in infertile and pregnant women seen at a public hospital in Southern Brazil.

\section{METHODS}

\section{Subjects}

A cross-sectional study in infertile and pregnant women seen at Hospital de Clínicas de Porto Alegre (HCPA) was conducted from January to December 2015. Participants were divided in two groups. The infertile group $(n=77)$ included women being treated at the infertility outpatient clinic of HCPA. They were unable to conceive after 1 year of regular unprotected sexual intercourse. The pregnant group $(n=60)$ included pregnant asymptomatic women of any gestational age. Exclusion criteria were similar for both groups: acute symptoms of PID, use of antibiotics during the last 30 days, age under 18 years old, and refusal to participate in the study. First-void urine (FVU) for CT "in house" Polymerase Chain Reaction (PCR) test and a single venous blood sample for indirect immunofluorescence (IIF) for CT serological testing were collected from all participating women. Additionally, all women answered a questionnaire about their sexual and gynecological medical history.

\section{Laboratory Methods}

Antibody testing was performed by IIF in blood samples at the Hospital de Clínicas de Porto Alegre laboratory. The commercial kit Viro-Immun (VIRO-IMMUN
Labor-Diagnostika GmbH Oberursel /Germany) was used. FVU samples were immediately shipped to Amplicon laboratory, and PCR was performed using an "in house" method developed according to previous studies ${ }^{10,11}$.

\section{Ethical Aspects}

The study was approved by the Research Ethics Committee of the Hospital de Clínicas de Porto Alegre, and all patients were informed about this study through the informed consent form.

\section{Statistical Analysis}

The sample size was calculated using the WinPEPI program (Programs for Epidemiologists for Windows) 11.43 version and was based on previous findings of IgG prevalence (39\% in infertile women and $19 \%$ in pregnant women $)^{12}$. Considering a $95 \%$ confidence interval and a statistical power of $71.6 \%$, we included $\mathrm{n}=77$ infertile and $\mathrm{n}=60$ pregnant participants. Data processing and analyses were performed using the SPSS 21.0 (SPSS, Chicago, III, USA). Initially, a descriptive analysis of the main characteristics of the participants and their related risk factors was performed. Quantitative variables were expressed as mean and standard deviation (mean $\pm S D$ ) or median value and interquartile amplitude (median $\pm I Q$ ). Categorical variables were expressed as absolute and relative frequencies. We used the t-student test to compare quantitative variables. The Mann-Whitney $U$ test was used when data distribution was asymmetrical. Pearson's chi-squared test or Fisher's exact test were applied to sets of categorical data. We also calculated IgG's sensitivity, specificity, positive and negative predictive value, the accuracy and the odds ratio to predict TFI. $\mathrm{P} \leq 0.05$ was considered statistically significant.

\section{RESULTS}

FVU and serum samples of 60 healthy pregnant women and 77 infertile women were investigated. Pregnant women were younger and had lower rates of steady sexual partner, previous PID, and previous pelvic surgery than the infertile group. They also had higher rates of regular condom use. The characteristics of the sample are summarized in Table 1. The mean gestational age was 30.6 weeks $( \pm 7.4)$ among pregnant women. In the infertile group, median time of infertility was 6 years (3-10). Primary infertility was found in $84.4 \%$ of women and $54 \%$ of them had tubal damage. Sixteen women $(20.8 \%)$ suffered from more than one cause of infertility (table 2). We found statistically similar prevalence rates of PCR and IgG antibodies between the groups. However, 
infertile women had higher median of $\lg G$ titration (table 3). When we compared the TFI subgroup with controls, there were statistically more individuals with high titration $(\lg G \geq 128)$ levels among infertile women (table 4). Sensitivity, specificity, positive predictive value (PPV), negative predictive value (NPV), accuracy, and odds ratio were calculated concerning IgG's ability to predict tubal damage (table 5). We found association between positive IgG antibody test and higher number of sexual partners in life (table 6). IgG high titration level (IgG $\geq 128$ ) was associated with younger age of first sexual intercourse, higher number of sexual partners and smoking (table 7). Individuals with TFI were more likely to have previous history of PID than women with other causes of infertility (table 8).

Table 1: Sample characteristics.

\begin{tabular}{lccr}
\hline \multicolumn{1}{c}{ Variables } & Infertile $(\mathbf{n}=\mathbf{7 7})$ & Pregnant $(\mathbf{n}=\mathbf{6 0})$ & p \\
\hline Age (years) - mean \pm SD & $32.8 \pm 4.4$ & $27.1 \pm 6.4$ & $<0.001$ \\
Number of pregnancies - median (P25 - P75) & $0(0-1)$ & $2(1-3)$ & $<0.001$ \\
Previous abortion - n(\%) & $20(26.0)$ & $13(21.7)$ & 0.701 \\
Age of first sexual intercourse (years) - mean \pm SD & $16.4 \pm 2.3$ & $16.3 \pm 1.9$ & 0.710 \\
Number of sexual partners - median (P25 - P75) & $3(1-4.5)$ & $3(2-5)$ & 0.488 \\
Steady sexual partner - $\mathrm{n}(\%)$ & $77(100)$ & $55(91.7)$ & 0.015 \\
Regular condom use - $\mathrm{n}(\%)$ & $4(5.2)$ & $15(25.0)$ & 0.002 \\
Previous PID - $\mathrm{n}(\%)$ & $25(32.5)$ & $2(3.3)$ & $<0.001$ \\
Previous ectopic pregnancy - $\mathrm{n}(\%)$ & $7(9.1)$ & $1(1.7)$ & 0.079 \\
Previous pelvic surgery - $\mathrm{n}(\%)$ & $33(42.9)$ & $3(5.0)$ & $<0.001$ \\
Previous HPV infection - $\mathrm{n}(\%)$ & $12(15.6)$ & $4(6.7)$ & 0.179 \\
Smoking - $\mathrm{n}(\%)$ & $10(13.0)$ & $4(6.7)$ & 0.354 \\
\hline
\end{tabular}

$\mathrm{SD}=$ standard deviation; $\mathrm{PID}=$ pelvic inflammatory disease; $\mathrm{HPV}=$ human papilloma virus.

Table 2: Characteristics of the infertile group.

\begin{tabular}{lc}
\hline \multicolumn{1}{c}{ Variables } & Infertile $\mathbf{( n = 7 7 )}$ \\
\hline Previous empirical treatment $-\mathrm{n}(\%)$ & $33(42.9)$ \\
Primary infertility - $\mathrm{n}(\%)$ & $65(84.4)$ \\
Time of infertility (years) - median (P25 - P75) & $6(3-10)$ \\
Causes of infertility - $\mathrm{n}(\%)$ & \\
Tubal damage & $42(54.5)$ \\
Other causes & $47(61.0)$ \\
$\quad$ Anovulation & $11(14.3)$ \\
Endometriosis & $15(19.5)$ \\
Male & $20(26.0)$ \\
$\quad$ Uterine & $1(1.3)$ \\
Multiple causes $-\mathrm{n}(\%)$ & $16(20.8)$ \\
\hline
\end{tabular}

Table 3: Prevalence of CT IgG and PCR in groups.

\begin{tabular}{lccc}
\hline \multicolumn{1}{c}{ CT test } & Infertile $(\mathbf{n}=\mathbf{7 7})$ & Pregnant $(\mathbf{n}=\mathbf{6 0})$ & $\mathbf{p}$ \\
\hline IgG- $\mathrm{n}(\%)$ & & & 0.733 \\
Positive & $47(61.0)$ & $34(56.7)$ & \\
$\quad$ Negative & $30(39.0)$ & $26(43.3)$ & $128(64-256)$ \\
IgG titration- median (P25-P75) & $256(128-512)$ & $19(31.7)$ & 0.016 \\
IgG $\geq 128-\mathrm{n}(\%)$ & $39(50.6)$ & & 0.040 \\
PCR & & $0(0.0)$ & 1.000 \\
Positive & $1(1.3)$ & $60(100)$ & \\
Negative & $76(98.7)$ & & \\
\hline
\end{tabular}

IgG = immunoglobulin G; PCR = Polymerase Chain Reaction. 
Table 4: Prevalence of CT IgG and PCR in the tubal factor infertility subgroup and in pregnant women.

\begin{tabular}{lccc}
\hline \multicolumn{1}{c}{ CT test } & TFI infertility $(\mathbf{n}=\mathbf{4 2})$ & Pregnant $(\mathbf{n}=\mathbf{6 0})$ & $\mathbf{p}$ \\
\hline IgG & & & 0.571 \\
$\quad$ Positive & $27(64.3)$ & $34(56.7)$ & \\
$\quad$ Negative & $15(35.7)$ & $26(43.3)$ & 0.002 \\
IgG titration - median (P25-P75) & $256(128-512)$ & $128(64-256)$ & 0.005 \\
IgG $\geq 128-\mathrm{n}(\%)$ & $26(61.9)$ & $19(31.7)$ & - \\
PCR & & & \\
$\quad$ Positive & $0(0.0)$ & $0(0.0)$ & \\
$\quad$ Negative & $42(100)$ & $60(100)$ & \\
\hline
\end{tabular}

$\mathrm{TFI}$ = tubal factor infertility; IgG = immunoglobulin G; PCR = Polymerase Chain Reaction.

Table 5: IgG diagnostic properties in predicting tubal damage.

\begin{tabular}{lccc}
\hline \multicolumn{1}{c}{ Diagnostic properties } & Positive (>0) & IgG $\mathbf{2 1 2 8}$ & IgG $\mathbf{2}$ 256 \\
\hline Sensitivity & $64.3 \%$ & $61.9 \%$ & $47.6 \%$ \\
Specificity & $42.9 \%$ & $62.9 \%$ & $71.4 \%$ \\
PPV & $57.4 \%$ & $66.7 \%$ & $66.7 \%$ \\
NPV & $50.0 \%$ & $57.9 \%$ & $53.2 \%$ \\
Accuracy & $54.5 \%$ & $62.3 \%$ & $58.4 \%$ \\
Odds ratio & 1.35 & 2.75 & 2.27 \\
\hline
\end{tabular}

$\mathrm{PPV}=$ positive predictive value; NPV = negative predictive value.

Table 6: Association between participants' characteristics and IgG positivity.

\begin{tabular}{lccc}
\hline \multicolumn{1}{c}{ Variables $^{*}$} & $\begin{array}{c}\text { IgG Positive (IgG >0) } \\
(\mathbf{n}=\mathbf{8 1})\end{array}$ & $\begin{array}{c}\text { IgG Negative (IgG=0) } \\
(\mathbf{n = 5 6 )}\end{array}$ & $\mathbf{p}$ \\
\hline Age & $30.6 \pm 5.7$ & $29.8 \pm 6.5$ & 0.423 \\
Age of first sexual intercourse & $16.1 \pm 2.1$ & $16.8 \pm 2.0$ & 0.060 \\
Number of sexual partners & $3(2-5)$ & $2(1-4)$ & 0.036 \\
Steady sexual partner & $77(95.1)$ & $55(98.2)$ & 0.648 \\
Condom use & $13(16.0)$ & $6(10.7)$ & 0.524 \\
Previous PID & $17(21.0)$ & $10(17.9)$ & 0.815 \\
Previous ectopic pregnancy & $6(7.4)$ & $2(3.6)$ & 0.471 \\
Previous pelvic surgery & $26(32.1)$ & $10(17.9)$ & 0.096 \\
Previous HPV infection & $11(13.6)$ & $5(8.9)$ & 0.574 \\
Smoking & $11(13.6)$ & $3(5.4)$ & 0.202 \\
Number of pregnancies & $1(0-2)$ & $1(0-2)$ & 0.186 \\
\hline
\end{tabular}

* Expressed as mean \pm SD, median (percentile 25-75) or $\mathrm{n}(\%)$. PID = pelvic inflammatory disease; HPV = human papilloma virus.

Table 7: Association between participants' characteristics and IgG titration.

\begin{tabular}{lccc}
\hline \multicolumn{1}{c}{ Variables* } & $\begin{array}{c}\text { High titration } \\
(\mathbf{I g G} \geq \mathbf{1 2 8}) \\
(\mathbf{n = 5 8 )}\end{array}$ & $\begin{array}{c}\text { Low titration } \\
(\mathbf{I g G < 1 2 8 )} \\
(\mathbf{n = 7 9 )}\end{array}$ & $\mathbf{p}$ \\
\hline Age & $30.5 \pm 5.3$ & $30.1 \pm 6.6$ & 0.743 \\
Age of first sexual intercourse & $15.7 \pm 1.9$ & $16.8 \pm 2.2$ & 0.002 \\
Number of sexual partners & $3.5(2-7)$ & $2(1-4)$ & 0.007 \\
Steady sexual partner & $54(93.1)$ & $78(98.7)$ & 0.162 \\
Condom use & $10(17.2)$ & $9(11.4)$ & 0.466 \\
Previous PID & $15(25.9)$ & $12(15.2)$ & 0.182 \\
Previous ectopic pregnancy & $6(10.3)$ & $2(2.5)$ & 0.071 \\
Previous pelvic surgery & $20(34.5)$ & $16(20.3)$ & 0.094 \\
Previous HPV infection & $8(13.8)$ & $8(10.1)$ & 0.696 \\
Smoking & $10(17.2)$ & $4(5.1)$ & 0.041 \\
Number of pregnancies & $1(0-2)$ & $1(0-2)$ & 0.912 \\
\hline
\end{tabular}

* Expressed as mean \pm SD, median (percentile 25-75) or $\mathrm{n}(\%)$. PID = pelvic inflammatory disease; HPV = human papilloma virus. 
Table 8: Association between participants' characteristics and tubal factor infertility.

\begin{tabular}{lccc}
\hline \multicolumn{1}{c}{ Variables* $^{*}$} & $\begin{array}{c}\text { Tubal factor infertility } \\
(\mathbf{n = 4 2 )}\end{array}$ & $\begin{array}{c}\text { Other causes of } \\
\text { infertility } \\
(\mathbf{n = 3 5 )}\end{array}$ & $\mathbf{p}$ \\
\hline Age & $32.7 \pm 4.1$ & $32.9 \pm 4.7$ & 0.825 \\
Number of pregnancies & $0(0-2)$ & $0(0-1)$ & 0.094 \\
Age of first sexual intercourse & $16.2 \pm 1.7$ & $16.7 \pm 2.8$ & 0.347 \\
Number of sexual partners & $3(1-5)$ & $3(1-4)$ & 0.354 \\
Condom use & $2(4.8)$ & $2(5.7)$ & 1.000 \\
Previous PID & $22(52.4)$ & $3(8.6)$ & $<0.001$ \\
Previous ectopic pregnancy & $6(14.3)$ & $1(2.9)$ & 0.119 \\
Previous pelvic surgery & $20(47.6)$ & $13(37.1)$ & 0.488 \\
Previous HPV infection & $8(19.0)$ & $4(11.4)$ & 0.547 \\
Smoking & $5(11.9)$ & $5(14.3)$ & 1.000
\end{tabular}

* Expressed as mean \pm SD, median (percentile $25-75$ ) or $n(\%)$. PID = pelvic inflammatory disease; HPV = human papilloma virus.

\section{DISCUSSION}

Using different diagnostic methods, we found no significant differences between fertile and infertile women for CT infection. This study found a $61 \%$ prevalence of CT IgG antibodies in infertile women and $56.7 \%$ in pregnant women. A study conducted in India ${ }^{13}$ found a $68 \%$ prevalence of CT IgG antibodies in infertile women and $10 \%$ in healthy pregnant women. Siemer et al. ${ }^{12}$ also showed statistically different prevalence rates of CT IgG between infertile and pregnant women (39\% vs. $19 \%$, respectively). Rashidi et al. ${ }^{14}$, using ELISA to test IgG antibodies, observed lower rates of seroprevalence and found no difference between infertile and pregnant women ( $9 \%$ vs. $5 \%$, respectively). In our study, the high prevalence of CT antibodies in pregnant women may be caused by cross-reaction with $C$. pneumoniae, because most serological tests are not speciesspecific tests.

PCR in FVU was positive in only one (1.3\%) infertile woman and in none of the pregnant participants. Previous studies in Brazil have found variable prevalence rates of CT using NAATs. Ramos et al. ${ }^{15}$ tested 161 women between 15 and 44 years old in Porto Alegre-RS and found a $0.59 \%$ CT prevalence in urine samples. Two multicenter studies were conducted in Brazil to estimate CT prevalence in pregnancy and found a $9.8 \%$ prevalence when FVU was used to perform PCR analysis, whereas a $9.4 \%$ prevalence was found when hybrid capture was performed in endocervical swabs ${ }^{16,17}$.

Some authors believe that CT IgG antibodies are as accurate as hysterosalpingography (HSG) in predicting $\mathrm{TFI}^{18}$. In our study, IgG titration of 128 had better diagnostic properties in predicting tubal damage. Nevertheless, our findings regarding
IgG were worse than previous studies. Malik et al. ${ }^{19}$ found $72.7 \%$ sensitivity, $80 \%$ PPV, $77.7 \%$ specificity, and $70 \%$ NPV of IgG antibodies measured by ELISA. A meta-analysis performed in 2008 indicated that the predictive value of CT antibody test for tubal pathology is limited: its sensitivity varies between $30 \%$ and $88 \%$, whereas its specificity varies between $45 \%$ and $100 \%{ }^{20}$.

We found correlation between $\lg G$ presence and younger age of first sexual intercourse, higher number of sexual partners, and smoking. This finding agrees with previous studies. Datta et al. ${ }^{21}$ concluded that age under 25 years old, multiple sexual partners, irregular use of condom, and previous history of any sexual transmitted disease are risk factors for CT infection.

A limitation of our study is that pregnant women were tested mostly in the third quarter of pregnancy. Therefore, we could not differentiate infections that occurred previously or during pregnancy. Besides that, the low prevalence of positive PCR in infertile women could be explained by the fact that almost $43 \%$ of them had documented previous empirical treatment with azithromycin during infertility investigation. Furthermore, CT may persist in a viable and metabolically active state in the upper genital tract, despite negative PCR results in urine or endocervical samples ${ }^{22}$. In addition, we have to consider that the mean age in our study population was relatively high, and more than $91 \%$ of women in our population had a steady sexual partner. Because most CT infections occur in people younger than 25 years old who are sexually promiscuous, the high seroprevalence of CT and the low rates of positive PCR found in our study are understandable. 
In conclusion, we demonstrated a statistically similar high prevalence of CT IgG antibody in Brazilian pregnant and infertile women, but a low prevalence of positive PCR in urine samples. CT antibodies were associated with sexual behavior and smoking.

\section{Acknowledgements}

We thank the Fundo de Apoio à Pesquisa - Hospital de Clínicas de Porto Alegre (FIPE-HCPA) for the financial support.

\section{REFERENCES}

1. Weinstock $\mathrm{H}$, Berman $\mathrm{S}$, Cates $\mathrm{W}$ JR. Sexually transmitted diseases among American youth: incidence em prevalence estimates, 2000. Perspect Sex Reprod Health. 2004;36(1):6-10. http://dx.doi.org/10.1363/3600604. PMid:14982671.

2. Newman L, Rowley J, Vander Hoorn $\mathrm{S}$, Wijesooriya NS, Unemo M, Low $\mathrm{N}$, et al. Global estimates of the prevalence and incidence of four curable sexually transmitted infections in 2012 based on systematic review and global reporting. PLoS One. 2015;10(12):e0143304. http://dx.doi. org/10.1371/journal.pone.0143304. PMid:26646541.

3. Wilson JS, Honey E, Templeton A, Paavonen J, Mardh PA, StaryPerdersen A, et al. A systematic review of the prevalence of Chlamydia trachomatis among European women. Hum Reprod Update. 2002;8(4):38594. http://dx.doi.org/10.1093/ humupd/8.4.385. PMid:12206472.

4. Brunham RC, Rappuoli R. Chlamydia trachomatis control requires a vaccine. Vaccine. 2013;31(15):18927. http://dx.doi.org/10.1016/j. vaccine.2013.01.024. PMid:23375977.

5. Oakeshott P, Kerry S, Aghaizu A, Atherton H, Hay S, Taylor-Robinson $D$, et al. Randomised controlled trial of screening for Chlamydia trachomatis to prevent pelvic inflammatory disease: the POPI (prevention of pelvic infection) trial. BMJ. 2010;340:c1642.

6. Silva MJPMA, Florêncio GL, Gabiatti $\mathrm{JR}$, Amaral RL, Eleutério J Jr, Gonçalves AK. Perinatal morbidity and mortality associated with chlamydial infection: a meta-analysis study. Braz J Infect Dis. 2011;15(6):533-9. http://dx.doi.org/10.1590/S141386702011000600006 . PMid:22218511.

7. Bekler C, Kultursay N, Ozacar T, Sayiner A, Yalaz M, Akisu M. Chlamydial infections in term and preterm neonates. Jpn J Infect Dis. 2012;65(1):1-6. PMid:22274150.
8. Papp JR, Schachter J, Gaydos CA, Van Der Pol B. Recommendations for the Laboratory-Based Detection of Chlamydia trachomatis and Neisseria gonorrhoeae - 2014. MMWR Recomm Rep. 2014;63:1-19. PMid:24622331.

9. Land JA, Van Bergen JE, Morré SA, Postma MJ. Epidemiology of Chlamydia trachomatis infection in women and the cost-effectiveness of screening. Hum Reprod Update. 2010;16(2):189-204. http://dx.doi. org/10.1093/humupd/dmp035. PMid:19828674.

10. Bobo L, Coutlee F, Yolken RH, Quinn T, Viscidi RP. Diagnosis of Chlamydia trachomatis cervical infection by detection of amplified DNA with an enzyme immunoassay. J Clin Microbiol. 1990;28(9):1968-73. PMid:2229379.

11. Hartley JC, Kaye S, Stevenson S, Bennett J, Ridgway G. PCR detection and molecular identification of Chlamydiaceae species. J Clin Microbiol. 2001;39(9):3072-9. http:// dx.doi.org/10.1128/JCM.39.9.30723079.2001. PMid:11526131.

12. Siemer J, Theile $O$, Larbi $Y$, Fasching PA, Danso KA, Kreienberg R, et al. Chlamydia trachomatis infection as a risk factor for infertility among women in Ghana, West Africa. Am J Trop Med Hyg. 2008;78(2):323-7. PMid:18256439.

13. Sharma K, Aggarwal A, Arora U. Seroprevalence of Chlamydia trachomatis in women with bad obstetric history and infertility. Indian J Med Sci. 2002;56(5):216-7. PMid:12649942.

14. Rashidi BH, Chamani-Tabriz L, Haghollahi F, Jeddi-Tehrani M, Naghizadeh MM, Shariat M, et al. Effects of Chlamydia trachomatis infection on fertility; a case-control study. J Reprod Infertil. 2013;14(2):6772. PMid:23926567.

15. Ramos MC, Becker D, Germany C. Chlamydia trachomatis and Neisseria gonorrhoeae prevalence among women living in a low income neighborhood: a populational survey in Porto Alegre, Brazil. J Bras Doenças Sex Transm. 2003;15(2):2025.

16. Pinto VM, Szwarcwald CL, Baroni C, Stringari LL, Inocêncio LA, Miranda AE. Chlamydia trachomatis prevalence and risk behaviors in parturient women aged 15 to 24 in Brazil. Sex Transm Dis. 2011;38(10):957-61. http://dx.doi. org/10.1097/OLQ.0b013e31822037fc. PMid:21934572.

17. Jalil EM, Pinto VM, Benzaken AS, Ribeiro D, Oliveira EC, Garcia EG, et al. Prevalence of Chlamydia and Neisseria gonorrhoeae infections in pregnant women in six Brazilian cities. Rev Bras Ginecol Obstet. 2008;30(12):614-9. PMid:19219343.

18. Perquin DA, Beersma MF, de Craen AJ, Helmerhorst FM. The value of chlamydia trachomatisspecific IgG antibody testing and hysterosalpingography for predicting tubal pathology and occurrence of pregnancy. Fertil Steril. 2007;88(1):224-6. http://dx.doi. org/10.1016/j.fertnstert.2006.11.078. PMid:17296194.

19. Malik A, Jain S, Rizvi M, Shukla I, Hakim S. Chlamydia trachomatis infection in women with secondary infertility. Fertil Steril. 2009;91(1):91-5. http://dx.doi. org/10.1016/j.fertnstert.2007.05.070. PMid:18635168.

20. Sönmez S, Sönmez E, Yasar L, Aydin F, Coskun A, Süt N. Can screening Chlamydia trachomatis by serological tests predict tubal damage in infertile patients? New Microbiol. 2008;31(1):75-9. PMid:18437844.

21. Datta SD, Sternberg M, Johnson RE, Berman S, Papp JR, McQuillan $\mathrm{G}$, et al. Gonorrhea and chlamydia in the United States among persons 14 to 39 years of age, 1999 to 2002 . Ann Intern Med. 2007;147(2):89-96. http:// dx.doi.org/10.7326/0003-4819-147-2200707170-00007. PMid:17638719. 
22. Machado ACS, Guimarães EMB, Sakurai E, Fioravante FCR Amaral WN, Alves MFC. High titers of Chlamydia trachomatis antibodies in Brazilian women with tubal occlusion or previous ectopic pregnancy. Infect Dis Obstet

Gynecol. 2007;2007:24816. http:// dx.doi.org/10.1155/2007/24816 .

PMid:17541464.

Received: June 02, 2016

Accepted: Aug 02, 2016 